\title{
Síndrome de Ramsay Hunt y meningitis linfocitaria por virus varicela zoster en una paciente anciana
}

\author{
Ramsay Hunt syndrome and lymphocytic meningitis \\ due to varicella-zoster virus in an elderly woman
}

\author{
Pablo Ruiz Sada, Alfonso Gutiérrez Macías, Itziar Garmendia Antía, Miriam López Martínez \\ Servicio de Medicina Interna. Hospital Universitario Basurto. Osakidetza. Bilbao
}

\begin{abstract}
Resumen
Presentamos un caso de una paciente anciana con un síndrome de Ramsay Hunt (SRH) (herpes zóster ótico) con afectación de múltiples pares craneales (VII, VIII y V) que presentó simultáneamente una meningitis linfocitaria por virus varicela zóster y que evolucionó favorablemente con esteroides y aciclovir. Se revisan las principales características del SRH, haciendo énfasis en la coexistencia simultánea de afectación de múltiples pares craneales y meningitis linfocitaria en una paciente anciana inmunocompetente.
\end{abstract}

Palabras clave. Síndrome de Ramsay Hunt. Meningitis linfocitaria. Virus varicela-zóster.

\section{Introducción}

El síndrome de Ramsay Hunt (SRH), o herpes zóster ótico, consiste en una parálisis facial periférica secundaria a la reactivación de la infección por el virus varicela-zoster (WZ) a partir del ganglio geniculado del VII par craneal. Ocasionalmente existe afectación de otros pares craneales, generalmente el VIII, y con menor frecuencia otros ${ }^{1}$. Supone entre el 3-15\% de las parálisis faciales periféricas no traumáticas y los pacientes inmunodeprimidos están más expuestos a su desarrollo y a presentar cuadros de mayor gravedad ${ }^{1,2}$. Por otra parte, la afección del sistema nervioso central por el WZ está constituida por cuadros de isquemia o encefalitis en relación con vasculitis, mielitis, meningitis y ventriculitis ${ }^{3,4}$. Presentamos un caso de SRH con afectación de múltiples pares craneales y meningitis por WZ en una paciente anciana inmunocompetente.

\section{Caso clínico}

Mujer de 78 años con antecedentes de hipertensión arterial y síndrome depresivo en tratamiento con telmisartán y escitalopram. Acude por cuadro de instauración brusca de desorientación, tendencia al sueño y fiebre. En los días previos refería dolor en cavidad oral relacionado con la deglución y tumefacción dolorosa en pabellón auricular izquierdo, a los que se añadieron posteriormente hipoacusia y acúfenos en oído izquierdo e inestabilidad para la marcha. En la exploración destacaban rigidez de nuca, lesión eritematosa en pilar amigdalino izquierdo y lesiones vesiculosas escasas en pabellón auricular homolateral. La exploración neurológica puso de manifiesto la existencia de parálisis facial periférica izquierda e hipoestesia en hemicara izquierda. La marcha era discretamente inestable, con ampliación de la base de sustentación, sin lateropulsión y la prueba de Romberg fue negativa. No existía nistagmo; la exploración del resto de pares craneales y el

\section{Summary}

We present a case of Ramsay Hunt syndrome (RHS) (herpes zoster oticus) with multiple cranial nerve involvement (VII, VIII, and V nerves) and lymphocytic meningitis due to varicella-zoster virus in an elderly woman. Clinical evolution was satisfactory with aciclovir and steroids. We review the main characteristics of RHS, underscoring the coexistence of multiple cranial root involvement and lymphocytic meningitis in an elderly immunocompetent host.

Key words. Ramsay-Hunt syndrome. Lymphocytic meningitis. Varicellazoster virus

resto de la exploración neurológica fueron normales.

Entre las exploraciones complementarias destacaban hemoglobina $11,7 \mathrm{~g} / \mathrm{dL}$, leucocitos $6.200 / \mathrm{mm}^{3}$ y proteína C reactiva $2,7 \mathrm{mg} / \mathrm{d}$. La radiografía de tórax y TC craneal no mostraron hallazgos significativos. La RM cerebral mostró lesiones en sustancia blanca de naturaleza isquémica crónica. Se realizó una punción lumbar obteniendo líquido cefalorraquídeo (LCR) claro con 46 leucocitos (93\% mononucleares), glucosa $36 \mathrm{mg} / \mathrm{dL}$ y proteínas $90 \mathrm{mg} / \mathrm{dL}$. La PCR para WZ fue positiva. La determinación de adenosin desaminasa fue normal, los cultivos aerobio y para micobacterias y la PCR para VH1 y VH2 fueron negativos. La audiometría mostró una hipoacusia neurosensorial bilateral. Fue tratada con aciclovir intravenoso (10 mg/kg/8h), durante 10 días y prednisona $60 \mathrm{mg} /$ día en pauta descendente durante 3 semanas. La evolución fue satisfactoria; a los 2 meses del alta se observó recuperación total de la parálisis facial y de la hipoestesia facial, persistiendo hipoacusia izquierda y ligera inestabilidad para la marcha.

\section{Discusión}

La primoinfección por WZZ produce la varicela, tras la cual el virus permanece en estado latente en los ganglios de las raíces raquídeas posteriores y en los ganglios sensitivos de los nervios craneales ${ }^{3}$. La reactivación de la infección a partir de los ganglios raquídeos produce el herpes zóster, mientras que el SRH aparece si esta sucede a partir del ganglio geniculado². La afectación neurológica es más frecuente en inmunodeprimidos y ancianos, en relación con la afectación de la inmunidad celular inherente al proceso de envejecimiento ${ }^{5}$. La fisiopatología de las manifestaciones neurológicas reside en la capacidad del virus de replicarse activamente en las arterias produciendo arteritis que condiciona la isquemia de los territorios irrigados ${ }^{4}$. Las más frecuentes son mielitis, encefalitis, ventriculitis y arteritis de 
grandes vasos en pacientes inmunocompetentes y de pequeño vaso en inmunodeprimidos ${ }^{3}$. Todas ellas pueden presentarse en ausencia de las lesiones cutáneas características, por lo que el diagnóstico puede ser difícil.

EI SRH abarca un amplio espectro sintomático, desde la aparición de otalgia, vesículas y mínima paresia facial periférica, hasta la afectación de múltiples pares craneales, especialmente en inmunodeprimidos ${ }^{1}$. La afectación del VII par es prácticamente constante, el VIII par se encuentra involucrado en un $40-70 \%$, mientras que la afectación de múltiples pares craneales se observa en un $3 \%$ de los casos aproximadamente ${ }^{6}$. La clínica depende de los nervios craneales implicados; pueden afectarse Ios pares VII, VIII, V, X, XII, XI y VI en orden decreciente de frecuencia ${ }^{1,6}$, por lo que pueden aparecer parálisis facial, dolor, hipoacusia o acúfenos en el oído afectado, vértigo, parálisis del velo de paladar, desviación de lengua o úvula, alteraciones de la deglución, hipoestesia facial o diplopia ${ }^{7}$. La afectación de múltiples pares craneales puede explicarse por la extensión de la infección entre ganglios próximos o por la lesión vascular de ramas de la arteria carótida que los irrigan de forma común². En el SRH, como en otras manifestaciones neurológicas de la reactivación de la infección por WZZ, las lesiones cutáneas pueden estar ausentes ${ }^{8}$. El diagnóstico es fundamentalmente clínico, aunque puede apoyarse mediante el aislamiento del virus 0 análisis de reacción en cadena de la polimerasa en exudados óticos y/o líquido cefalorraquíde ${ }^{9}$.

En el SRH la recuperación funcional completa sin tratamiento se estima en torno al 20-30\%. En la actualidad, aún en ausencia de ensayos clínicos controlados adecuados, se acepta que el tratamiento de elección es la combinación de antivirales y esteroides, instaurados de forma precoz, en las primeras 72 horas desde el inicio de la clínica ${ }^{6,10}$. Los factores que influyen en una recuperación incompleta son el grado de afectación del nervio facial al diagnóstico, el retraso en la instauración del tratamiento, la edad avanzada y la presencia de comorbilidad, ${ }^{6,11}$. En resumen, presentamos un caso de SRH, con afectación de múltiples pares craneales, y meningitis por WVZ en una paciente anciana inmunocompetente, que presentó una buena evolución, con mínimas secuelas tras el tratamiento con aciclovir y esteroides.

\section{Bibliografía}

1. Martínez Oviedo A, Lahoz Zamarro MT, Uroz del Hoyo JJ. Síndrome de Ramsay-Hunt. An Med Interna (Madrid) 2007; 24: 31-4.

2. Sweeney CJ, Gilden DH. Ramsay Hunt syndrome. J Neurol Neurosurg Psychiatry. 2001; 71: 149-54.

3. Gilden DH, Kleinschmidt-DeMasters BK, Laguardia JJ, Mahalingam R, Cohrs RJ. Neurologic complications of the reativation of varicella-zoster virus. N Engl J Med. 2000; 342: 635-45.

4. Amlie-Lefond C, Jubelt B. Neurologic manifestations of varicella zoster virus infections. Curr Neurol Neurosci Rep 2009; 9: 430-4.

5. Mueller NH, Gilden DH, Cohrs RJ, Mahalingam R, Nagel MA. Varicella zoster virus infection: clinical features, molecular pathogenesis of disease, and latency. Neurol Clin 2008; 26: 675-97.

6. Shim HJ, Jung H, Park DC, Lee JH, Yeo SG. Ramsay Hunt syndrome with multicranial nerve involvement. Acta Otolaryngol 2011; 131 (2): 210-5.

7. Coulson S, Croxson GR, Adams R, Oey V. Prognostic factors in herpes zoster oticus (Ramsay Hunt syndrome). Otol Neurotol 2011; 32 (6): 1025-30.

8. Lee HY, Kim MG, Park DC, Park MS, Byun JY, Yeo SG. Zoster sine herpete causing facial palsy. Am J Otolaryngol 2012; 33: 565-71.

9. Boemo RL, Navarrete ML, García-Arumí AM, Copa SL, Graterol D, Scherdel EP. Síndrome de Ramsay Hunt: nuestra experiencia. Acta Otorrinolaringol Esp 2010; 6: 418-21.

10. de Ru JA, van Benthem PP. Combination therapy is preferable for patients with Ramsay Hunt syndrome. Otol Neurotol 2011; 32 (5): 852-5.

11. Ryu EW, Lee HY, Lee SY, Park MS, Yeo SG. Clinical manifestations and prognosis of patients with Ramsay Hunt syndrome. Am J Otolaryngol 2012; 33: 313-8. 